\title{
The dissolved yellow substance and the shades of blue in the Mediterranean Sea
}

\author{
A. Morel and B. Gentili \\ Laboratoire d'Océanographie de Villefranche, Université Pierre et Marie Curie (Paris 6), and CNRS/INSU, 06238 \\ Villefranche-sur-mer, CEDEX, France
}

Received: 26 June 2009 - Published in Biogeosciences Discuss.: 27 August 2009

Revised: 12 November 2009 - Accepted: 13 November 2009 - Published: 24 November 2009

\begin{abstract}
When the nominal algorithms commonly in use in Space Agencies are applied to satellite Ocean Color data, the retrieved chlorophyll concentrations in the Mediterranean Sea are recurrently notable overestimates of the field values. Accordingly, several regionally tuned algorithms have been proposed in the past to correct for this deviation. Actually, the blueness of the Mediterranean waters is not as deep as expected from the actual (low) chlorophyll content, and the modified algorithms account for this peculiarity. Among the possible causes for such a deviation, an excessive amount of yellow substance (or of chromophoric dissolved organic matter, CDOM) has been frequently cited. This conjecture is presently tested, by using a new technique simply based on the simultaneous consideration of marine reflectance determined at four spectral bands, namely at 412, 443, 490, and $555 \mathrm{~nm}$, available on the NASA-SeaWiFS sensor (Seaviewing Wide Field-of-view Sensor). It results from this test that the concentration in yellow colored material (quantified as $a_{y}$, the absorption coefficient of this material at $443 \mathrm{~nm}$ ) is about twice that one observed in the nearby Atlantic Ocean at the same latitude. There is a strong seasonal signal, with maximal $a_{y}$ values in late fall and winter, an abrupt decrease beginning in spring, and then a flat minimum during the summer months, which plausibly results from the intense photobleaching process favored by the high level of sunshine in these areas. Systematically, the $a_{y}$ values, reproducible from year to year, are higher in the western basin compared with those in the eastern basin (by about 50\%). The relative importance of the river discharges into this semi-enclosed sea, as well as the winter deep vertical mixing occurring in the northern parts of the basins may explain the high yellow substance background. The regionally tuned [Chl] algorithms, actually reflect the presence of an excess of CDOM with
\end{abstract}

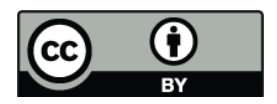

Correspondence to: A. Morel (morel@obs-vlfr.fr) respect to its standard (Chl-related) values. When corrected for the presence of the actual CDOM content, the [Chl] values as derived via the nominal algorithms are restored to more realistic values, i.e., approximately divided by about two; the strong autumnal increase is smoothed whereas the spring bloom remains as an isolated feature.

\section{Introduction}

The blue color of the Mediterranean Sea is legendary and rightly regarded as a sign of oligotrophic conditions. Sporadically and intermittently, however, this trophic status is modified. Indeed, in the northern parts of the Western and Eastern basins, vernal blooms develop leading to moderately high chlorophyll concentrations, and to a color shift toward bluegreen shades typical of meso- to eutrophic regimes. Satellite remote radiometry of Ocean Color is a technique which is intended to detect and map such color changes and interpret them in terms of optically influential constituents, in particular of phytoplankton abundance, quantified as chlorophyll concentration, [Chl] $\left(\mathrm{mg} \mathrm{m}^{-3}\right)$.

Yet, the first applications of this remote sensing technique to Mediterranean waters (using the data from the CZCS, the Coastal Zone Color Scanner from NASA, operating during the years 1979-1984) showed that the [Chl] retrieved from space was a notable overestimate of the true concentration as determined in situ (Gitelson et al., 1996; Antoine et al., 1995). Bricaud et al. (2002) and Antoine et al. (2008, their Fig. 14) arrived at the same conclusion when using the SeaWiFS data (Sea-viewing Wide Field-of-view Sensor). More accurately stated, the empirical algorithms, based on the ratio of ocean radiance (or reflectance) in the blue and green domains, which were routinely used to quantify [Chl], failed in the case of these waters. Not only remote radiometric determinations, but also in situ spectral measurements of waterleaving radiances, demonstrated that Mediterranean waters

Published by Copernicus Publications on behalf of the European Geosciences Union. 
are "greener" than it would normally result from their (generally low) phytoplankton content (Claustre et al., 2002).

This often observed color "anomaly" motivated the development of specifically tuned algorithms able to reconcile the remotely sensed [Chl] (using various sensors) with the field determinations, especially when [Chl] is low (D'Ortenzio et al., 2002; Bricaud et al., 2002; Volpe et al., 2007). As also noted by Gregg and Casey (2004), anomalous optical properties of the Mediterranean Sea (and Black Sea) entail a substantial and systematic positive bias of the nominal SeaWiFS returns with respect to in situ [Chl] data. By applying a rather tight criterion to the SeaWiFS data, Lee and Hu (2006, their Fig. 3) also showed that if Case-1 waters prevail in Mediterranean during summer, what they called "non-Case 1" waters would be present in the Western basin in Spring and Autumn, and in both (Western and Eastern) basins at wintertime. According to these authors, such departures from the Case-1 status would essentially be due to an increase in absorption by the "colored -or chromophoric- dissolved organic matter", or equivalently, "yellow substance". Beside the possible enhanced contribution of this absorbing material (e.g., Claustre and Maritorena, 2003), the presence of abundant coccoliths, or the episodic injection of aeolian dust, or even imperfect atmospheric corrections, were also suggested as possible causes for the persistent anomaly (Gregg and Casey, 2004; Claustre et al., 2002).

Another study (Morel et al., 2007a), however, strongly supported the hypothesis of an unusually high yellow substance content. This study was based on the consideration of the spectral diffuse attenuation coefficient, $K_{d}(\lambda)$. Indeed, an anomaly was detected which consisted of $K_{d}(\lambda)$ values in the blue part of the spectrum systematically exceeding the average values, that were expected from the [Chl] levels. Moreover, this anomaly was found to steadily increase when progressing into the UV domain, which is a typical trait of yellow substance absorption. Correlatively, the irradiance reflectance, $R(\lambda)$, was distinctly depressed in the near UV and blue parts of the spectrum, which can explain the failure of the standard algorithms. The same study also showed that the yellow substance absorption coefficient at $370 \mathrm{~nm}$ in the Mediterranean Sea, turns out to be at least twice its value in Pacific in spite of similar trophic conditions in terms of [Chl] values, (Fig. 9, ibid.). Along the same line, the depth of the euphotic layer is considerably reduced in the Mediterranean Sea with respect to its integrated [Chl] content (Morel and Gentili, 2004). Such a reduction can be explained if another absorbing agent is present in notable concentration and competes with algae in the bulk absorption process within the water column (Morel et al., 2007a, their Fig. 4).

A recently developed tool (Morel and Gentili, 2009), based on the simultaneous consideration of spectral marine reflectance, $R(\lambda)$, at four wavelengths allows the signatures of yellow absorbing substances (or chromophoric dissolved organic materials, denoted CDOM), and [Chl] to be disentangled. This technique can be applied to the Mediterranean
Sea to determine if the CDOM content is above the expected average level, and, as a consequence of such a positive deviation, if [Chl] could have been overestimated when using classical algorithms (see e.g., Hu et al., 2006). By systematically applying this discriminating tool to remotely sensed color data over the Mediterranean Sea, it will be possible to examine how, and when the CDOM-related anomaly, if any, is geographically and seasonally distributed within the Western and Eastern basins of this Sea.

\section{Methodology}

The technique developed to separately assess the yellow substance absorption coefficient at a given wavelength $\lambda$, hereafter denoted $a_{y}(\lambda)$ (expressed as $\mathrm{m}^{-1}$ ), and the chlorophyll concentration, [Chl], was described in detail elsewhere (Morel and Gentili, 2009). For completeness, the main features are summarized below. In Case- 1 waters, the above quantities were empirically found to be on average related through a non-linear relationship (Morel, 2009) of the form

$a_{y}(\lambda,[\mathrm{Chl}])=Y(\lambda)[\mathrm{Chl}]^{0.63}$

where the term $a_{y}$ was obtained through

$a_{y}(\lambda,[\mathrm{Chl}])=a_{t o t}(\lambda,[\mathrm{Chl}])-a_{w}(\lambda)-a_{p}(\lambda,[\mathrm{Chl}])$

i.e., by subtracting the pure water absorption, $a_{w}(\lambda)$ and the particle absorption, $a_{p}(\lambda$, [Chl]), from the total absorption, $a_{t o t}(\lambda,[\mathrm{Chl}])$. The spectral $a_{w}(\lambda)$ coefficients were adopted from Pope and Fry (1997), (from Morel et al., 2007c, for $\lambda=400 \mathrm{~nm}) ; a_{p}(\lambda,[\mathrm{Chl}])$, the particle absorption coefficients (algal plus non-algal particles), increase along with [Chl] according to power laws, which were adopted from Bricaud et al. (1998); the total absorption coefficients, $a_{t o t}(\lambda$, [Chl]), also depending on [Chl], were obtained by inversion of the spectral attenuation coefficient and spectral reflectance, $K_{d}(\lambda,[\mathrm{Chl}])$ and $R(\lambda,[\mathrm{Chl}])$, respectively (via Eq. 3 in Morel, 2009). In Eq. (1), the $Y(\lambda)$ coefficient decreases exponentially with $\lambda$, according to

$Y(\lambda)=Y\left(\lambda_{0}\right) \exp \left[-\mathrm{S}\left(\lambda-\lambda_{0}\right)\right]$

where $\lambda_{0}$ is a reference wavelength, and $S$ is the slope of the exponential decay for the spectral domain considered $(412-560 \mathrm{~nm})$. Equation (1) was initially established (Morel, 2009) for $\lambda=400 \mathrm{~nm}$ (Eq. 3)

$a_{y}(400,[\mathrm{Chl}])=0.0650[\mathrm{Chl}]^{0.63}$

By using Eq. (2) and letting $S=0.018 \mathrm{~nm}^{-1}$, the following expressions

$a_{y}(412,[\mathrm{Chl}])=0.0524[\mathrm{Chl}]^{0.63}$
$a_{y}(443,[\mathrm{Chl}])=0.0316[\mathrm{Chl}]^{0.63}$
$a_{y}(490,[\mathrm{Chl}])=0.0129[\mathrm{Chl}]^{0.63}$
$a_{y}(555,[\mathrm{Chl}])=0.0040[\mathrm{Chl}]^{0.63}$ 
can be derived for the particular wavelengths thereafter involved in the modeling computations.

The above Eq. (1) represents an "average" relationship in the sense that it statistically derives from a considerable number of optical data, namely the $a_{p}(\lambda,[\mathrm{Chl}]), K_{d}(\lambda,[\mathrm{Chl}])$, and $R(\lambda,[\mathrm{Chl}])$ coefficients, which were determined at differing seasons, in several zones of the world ocean, with various trophic situations corresponding to various [Chl] values. All these determinations, however, were made in environments well identified as belonging to Case- 1 waters. More specifically, the average character of Eq. (1) results from the adoption for the terms involved in Eq. (1') of the mean empirical relationships between the optical properties $a_{p}(\lambda), K_{d}(\lambda)$, $R(\lambda)$, and [Chl] (Morel, 2009). The algorithms used with ocean color data, either purely empirical, as OC4v4, or semianalytical, as OC4Me (Morel et al., 2007b) also rest on the same average bio-optical situation; indeed, they make use of the average relationships, either implicitly for OC4v4, or explicitly for OC4Me, which rests on the bio-optical model for Case-1 waters (Morel and Maritorena, 2001, hereafter denoted MM-01). Therefore these algorithms provide an exact [Chl] value only if the empirical relationships above are approximately verified.

The rationale behind the discriminating tool can be summarized as follows. It relies on the consideration of the reflectances, $R$, at $412,443,490$, and $555 \mathrm{~nm}$; they are combined to form two ratios, namely $R(412) / R(443)$ and $R(490) / R(555)$, simply written $R_{443}^{412}$ and $R_{555}^{490}$. Within the frame of the MM-01 model (slightly revised in Morel et al., $2007 \mathrm{~b}$ ), a unique relationship between $R_{443}^{412}$ and $R_{555}^{490}$ exists and can be numerically established. This relationship is graphically represented by the curve denoted $\Phi=1$ in Fig. 1a, b; it implicitly includes the average [CDOM]-[Chl] relationship (i.e., Eq. 1 and the derived Eq. 3a to d).

A rather high variability, however, around Eq. (1) occurs in natural environment, and the deviations observed in the Mediterranean Sea with respect to the standard $a_{y}(\lambda,[\mathrm{Chl}])$ values will be at the basis, and also the aim, of the present study. To account for this variability, deviations are simulated by introducing the factor $\Phi$, which numerically modifies the result of Eq. (1) (and thus of the derived Eq. 3a to d) according to

$a_{y}(\lambda,[\mathrm{Chl}])=\Phi \mathrm{Y}(\lambda)[\mathrm{Chl}]^{0.63}$

where the number $\Phi$ may be below or above unity, so that the simulated departure may be either a deficit or an excess of $\mathrm{CDOM}$ with respect to its reference [Chl]-dependent value. When $\Phi$ is given various discrete values differing from 1 , the $a_{y}(\lambda,[\mathrm{Chl}])$ absorptions values (Eq. 3a to d) are modified accordingly. When these modified values are introduced into the MM-01 model, a family of $R_{443}^{412}-R_{555}^{490}$ relationships can be produced. A family of such curves, generated for discrete $\Phi$ values, forms the "grid" which can be seen in Morel and Gentili (2009, their Fig. 2); instances of these curves are also displayed in Fig. 1a, b.
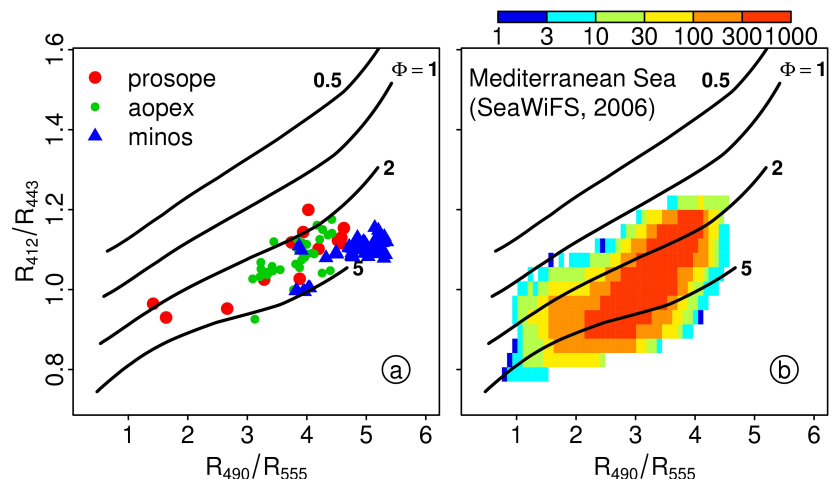

Fig. 1. Ratio of reflectance at 412 and $443 \mathrm{~nm}, R_{443}^{412}$, plotted as a function of the ratio $R_{555}^{490}$ (cf. Fig. 2, in Morel-Gentili, 2009); the theoretical (black) curves are computed for the standard situation $(\Phi=1$, Eq. 1), and when the yellow substance concentration is multiplied by $0.5,2$, or 5 , with respect to its Chl-dependent standard value (Eq. 4). (a) actual ratios determined at sea during the Prosope, Minos, and Aopex cruises (data and information available on http://www.obs-vlfr.fr/cd_rom_dmtt/pr_main.htm for Prosope, and on www.Ifremer.fr/sismer for Minos and Aopex) ; (b) same ratios derived from the SeaWifs data, during the whole 2006 year, taken as an example; for the 12 monthly composites, the total number of pixels is 364000 ; the number of occurrences is visualized through the frequency color scale.

When $R_{443}^{412}$ and $R_{555}^{490}$ have been simultaneously derived from measurements, at sea (Fig. 1a) or from space (Fig. 1b), these couples of actual values can be compared to those forming the family of curves, corresponding to various $\Phi$ values. From this comparison, a value of the factor $\Phi$ can be univocally determined. Practically, a lookup table (available at ftp://oceane.obs-vlfr.fr/pub/gentili/ CDOM-index-Table-interpol) allows such a determination to be made through an appropriate numerical interpolation.

It is important to emphasize that the adopted reference value, $Y(\lambda)$, does not influence the result of Eq. (4), which actually is determined by the product $\Phi Y(\lambda)$. The scale for $\Phi$, in particular its (arbitrary) neutral point $(\Phi=1)$ depends on the initial choice made for $Y(\lambda)$. Note also that the choice of the $S$-value above is not crucial when deriving the $\Phi$ factor (sensitivity study in Morel and Gentili, 2009).

\section{Dissolved and particulate absobing materials}

The nature of the materials (beside phytoplankton) responsible for the absorption in the blue part of the spectrum deserves some comments. According to the way it is derived, the $a_{y}$ term actually refers to, and is predominantly determined by, the absorption by the dissolved yellow substances (also called chromophoric dissolved organic matter, CDOM). However, those small sized non-algal particles (colored detrital material), able to pass through GF/F filters (effective pore size $\sim 0.5 \mu \mathrm{m}$ ), and thus not included in $a_{p}$, 
may also contribute to the formation of the present $a_{y}$ term (discussion in Morel, 2009). Therefore $a_{y}$ may slightly exceed the absorption by "truly" dissolved materials (operationally defined as those able to pass through a membrane filter with $0.2 \mu \mathrm{m}$ pore size). Note that the absorption coefficient (at $443 \mathrm{~nm}$ ), as retrieved via the "GSM" method (Siegel et al., 2002), and denoted $a_{\mathrm{CDM}}$ by these authors (where "CDM" stands for colored detrital material), describes the absorption by the dissolved organic matter (i.e., $a_{y}$ ), plus the absorption by non-algal (supposedly "detrital") particles. At least in principle, $a_{\mathrm{CDM}}$ must exceed the absorption by dissolved materials, yet by a small amount (see discussion "Is CDM dissolved or particulate?" in Siegel et al., 2002); it also must exceed the present $a_{y}$ term by an even smaller amount, since the tiny non-algal particles (those within the $0.5-0.2 \mu \mathrm{m}$ range) have already contributed to the formation of $a_{y}$ (Eq. 1'). Actually, the histograms of the $a_{\mathrm{CDM}}$ and $a_{y}$ distribution within the global ocean (shown in Morel and Gentili, 2009, their Fig. 7c-d,) show that $a_{\mathrm{CDM}}$ is systematically larger than $a_{y}$ by a small amount, however (10-15\%).

\section{Data}

SeaWiFS data (from NASA) are used in the present study, mainly as monthly composites. Normalized water-leaving radiances at $412,443,490$ and $555 \mathrm{~nm}$, which are already corrected for the bi-directional effects, are converted into irradiance reflectances by using the appropriate factors and relationships (see Appendix and Eq. A-6 in Morel and Gentili, 2009); then the ratios of these irradiance reflectances, $R_{443}^{412}$ and $R_{555}^{490}$, are computed and introduced into the lookup table mentioned above to derive the actual $\Phi$ value by interpolation.

The turbid coastal waters are identified through the enhancement of reflectance at $555 \mathrm{~nm}$, itself due to an enhancement of scattering, when sediment are present. The reflectance threshold above which turbid waters are detected (Morel and Bélanger, 2006) is based on the upper limit of the observed scattering-[Chl] relationship in case 1 waters; beside of being [Chl] dependent, this threshold is also geometrically dependent (on the sun-zenith angle). The corresponding pixels (generally within coastal zones and river plumes) are no longer considered in further analyses.

\section{Results}

When introduced into the $R_{443}^{412}-R_{555}^{490}$ plane, the ratios obtained from recent radiometric field determinations in the Mediterranean Sea (Fig. 1a) confirm the anomalously high yellow substance content; indeed, from these data, the yellow substance index $\Phi$ always exceeds 1 . Ratios of SeaWiFS reflectance also lead to the same conclusion (Fig. 1b). Therefore the yellow substances concentration in this Sea would systematically exceed what is expected from the [Chl] values by, at least, a factor 2 in most cases.

A map of the Mediterranean Sea is displayed in AppendixFig. A1 together with the geographical names used in what follows to describe the various regions and features.

\subsection{Geographical distribution and temporal evolution of the yellow substance index $(\Phi)$}

To ascertain the reality of a particular behavior of the Mediterranean Sea, it seems appropriate to compare this Sea to other geographical zones, submitted to a similar climate, yet with differing circulation patterns and hydrographic conditions. An instructive comparison can thus be obtained by considering the contiguous zone in the North East Atlantic, West of the Gibraltar Strait, at the same latitudes (between 30 and $\left.45^{\circ} \mathrm{N}\right)$, and of similar size $\left(5^{\circ}-35^{\circ} \mathrm{W}\right)$. To the extent that this Atlantic zone, off the Iberian peninsula and Moroccan coast (where coastal upwellings occur) might also be special, the entire zonal stripe extending from $30^{\circ}$ to $45^{\circ} \mathrm{N}$ and encompassing the whole ocean (Atlantic and Pacific) is also considered for reference.

In a first step, the comparison is based on the maps of the $\Phi$ factor within the Mediterranean and Atlantic zones, as derived from the SeaWiFS monthly composites. Instances of these maps are shown (Fig. 2) for the months of March and August, selected because they correspond to contrasted situations in terms of biological activity (vernal blooms versus oligotrophic summer conditions). In March, the lowest $\Phi$ values $(\sim 1.5-2)$ in the Mediterranean Sea are found south of the island of Rhodes (between the islands of Crete and Cyprus), and also off the Gulf of Lions, actually in those locations where the main algal blooms are known to take place (a weak bloom also occurs south of Sardinia). These minima in $\Phi$ do not indicate a lower CDOM content, but a lower relative content, in as much as [Chl] has increased up to $\sim 0.5-1.5 \mathrm{mg} \mathrm{m}^{-3}$ within these localized blooms, while the yellow substance absorption has remained rather unchanged. Apart from these restricted zones, high $\Phi$ values ( $>3)$ dominate everywhere within the entire Mediterranean Sea. In contrast, low $\Phi$ values prevail in the near Atlantic; there is even a zonal belt (roughly centered on $38^{\circ} \mathrm{N}$ ) where $\Phi$ is slightly below 1 , also in coincidence with the vernal bloom. This bloom, and the concomitant low $\Phi$ values, migrate northward during the following months (not shown).

The seasonal CDOM cycle in the Northern Hemisphere steadily exhibits a minimum in summer (Siegel et al., 2002; Morel and Gentili, 2009); consistently, in both the Atlantic and Mediterranean zones, the $\Phi$ values go through their minimal level $(\sim 1-2)$ around August. Higher values, however, are still present along the coast of Portugal (the seat of a coastal upwelling), and within the Gulf of Lions (probably related to the Rhone river discharge). The Aegean Sea, especially its northernmost part under the influence of the water exiting the Black Sea through the Bosporus, is 

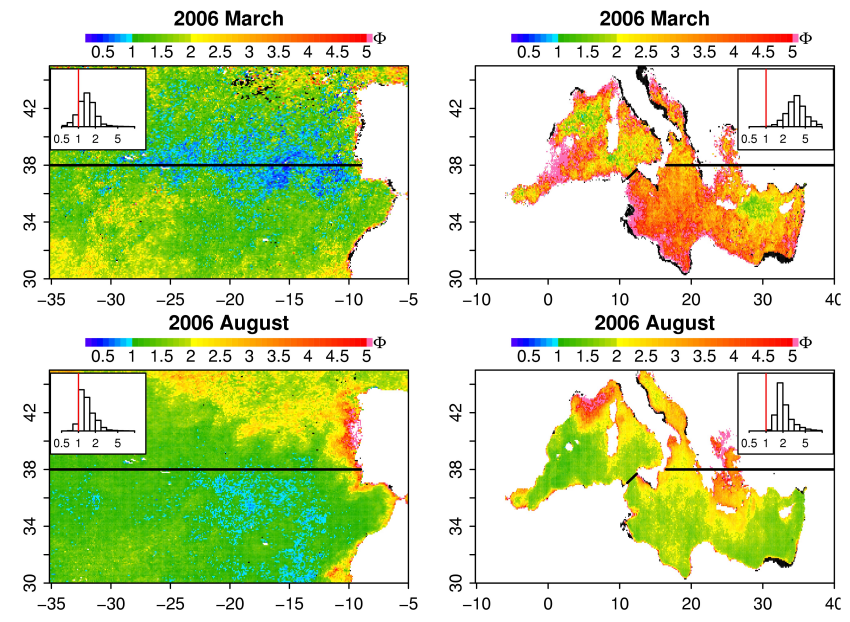

Fig. 2. Derived from SeaWiFS data for March (1st row) and August 2006 (2nd row), distribution of the $\Phi$ parameter within the Mediterranean Sea (right column), and within the Near-Atlantic (left column), between the latitudes $30^{\circ}$ and $45^{\circ} \mathrm{N}$ (see color scale). The black lines (the line between Tunisia and Sicily, and the 38th parallel) are the limits adopted for the Eastern and Western Mediterranean basins; the northern and southern sector in the Near Atlantic are also delimited by the 38th parallel. The black pixels correspond to waters identified as turbid. The frequency distributions of the pixels according to their $\Phi$ values are shown in insert.

permanently a zone with very high $\Phi$ values (no longer discussed). In the Black Sea, when not flagged as a turbid Case2 zone, the radiances at $412 \mathrm{~nm}$ are extremely low, and $\Phi$ values always extremely high. The importance of the river discharges (Danube, Don, Dnieper) into this Sea can explain such a situation, which is no longer examined in what follows.

The temporal evolutions of the various quantities associated with the CDOM content and the algal biomass are computed from the SeaWiFS monthly composites, and assembled in Fig. 3. Mean monthly values for $\Phi$, for [Chl] (before and after correction, see later), and for $a_{y}(443)$ are shown; these quantities are spatially averaged within each of five geographical zones, which are delimited as follows. The western and eastern Mediterranean basins are separately considered. Actually (see Fig. 2), the eastern basin has been limited northward by the $38^{\circ} \mathrm{N}$ parallel, which excludes the Aegean and Adriatic Seas and part of the Ionian Sea; the influence of the Black Sea and Marmora Sea (mentioned above), as well as that of the often turbid Adriatic Sea are thus discarded. With such borders, the two basins distinctly differ regarding their mean latitude; the Eastern and Western basins are located southward and northward of the $38^{\circ}$ parallel, respectively. For consistency, in particular with respect to solar illumination conditions and thus seasonal variations, the same $38^{\circ} \mathrm{N}$ parallel is also used to distinguish a northern sector and a southern sector within the near-Atlantic region. The zonal belt around the globe from $30^{\circ}$ to $45^{\circ} \mathrm{N}$ is not subdivided.
Globally, the Mediterranean $\Phi$ values are systematically above (up to twice) those in the neighboring Atlantic, or those of the whole ocean within the zonal $\left(30-45^{\circ} \mathrm{N}\right)$ belt (Fig. 3, upper row). Nevertheless, the $\Phi$ values are on average clearly larger than 1 everywhere within the belt, including in the eastern Atlantic; accordingly, there would exist at these latitudes a permanent excess of CDOM in comparison with the mean oceanic "state" (i.e., the state corresponding to $\Phi=1)$. Actually, when the whole ocean is considered the central (most frequent) $\Phi$ value is well unity (histograms in Morel and Gentili, 2009). In the Northern Hemisphere, however, and in particular at the latitudes considered, $\Phi$ is always above 1 (ibid., Fig. 5, and also Fig. 4 in Siegel et al., 2002). This observation is here confirmed.

A second observation deals with the annual $\Phi$ cycle within the Mediterranean Sea: it is distinctly more featured than outside at the same latitudes. After a minimum extending from June to September, the increase from October to December, especially in the western basin, is steeper in the Mediterranean Sea than in adjacent Atlantic. It must be noted that extended cloudiness and low solar illumination (which means difficult atmospheric correction) prevent fully reliable data from being derived in the northern part of the western basin around the winter solstice; the same statement could be repeated for the Adriatic Sea (not discussed thereafter).

The second row in Fig. 3 shows the temporal change in the monthly and spatially averaged algal [Chl] biomass, as retrieved in each zone using the OC4v4 algorithm (O'Reilly et al., 1998, 2000). Compared to the global Ocean, or to the near-Atlantic zone, there are some important particularities in the Mediterranean Sea. First of all, the [Chl] values in fall, and then the [Chl] maximum during the bloom in the Western basin (peaking in March) are higher than everywhere else. In the Eastern basin, after an earlier bloom (in February), an oligotrophic situation prevails over an extended summer period, like in the corresponding Southern Atlantic sector.

\subsection{Yellow substance absorption and chlorophyll assessment}

The $a_{y}(443)$ coefficient is then derived by inserting the actual $\Phi$ values into Eq. (4), to be written for $\lambda=443 \mathrm{~nm}$ with $Y=0.0316$ (cf. Eq. 3c); the [Chl] value to be inserted is the one directly provided by the OC4v4 algorithm, which tacitly includes the $\Phi=1$ hypothesis. Note that the absolute $a_{y}$ values must be regarded with some caution, as they might be affected by an inaccurate atmospheric correction, particularly at $412 \mathrm{~nm}$ (discussed later). Yet, relative comparisons of the $a_{y}(443)$ regional values, as made below, are safer.

The monthly mean $a_{y}(443)$ values are displayed for each region in the third row of Fig. 3. The seasonal $a_{y}$ variations are considerably more accentuated in the Mediterranean basins than in their Atlantic counterparts; year-round, the $a_{y}$ values in the Mediterranean eastern basin are systematically lower than those in the western basin. The prominent feature 

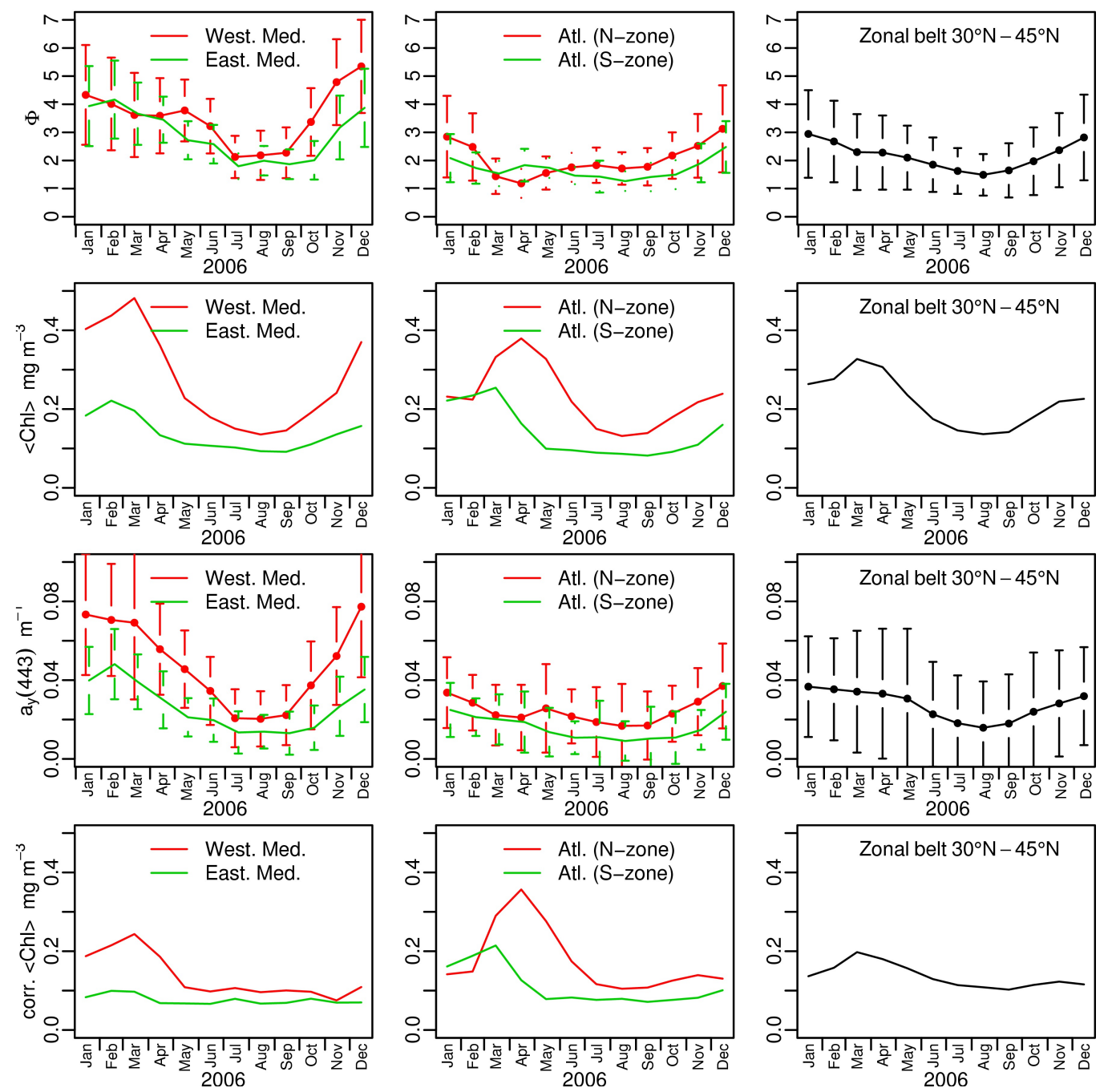

Fig. 3. From SeaWiFS data, seasonal course during the year 2006 of the monthly mean $\Phi$ values (first row) for each of the five regions as indicated in inserts; second row, for the same regions, monthly mean [Chl] values $\left(\mathrm{mg} \mathrm{m}^{-3}\right)$, as derived via the OC4v4 algorithm; third row, monthly mean $a_{y}(443)$ values $\left(\mathrm{m}^{-1}\right)$; last row, corrected [Chl] values (see text) for the same zones. Vertical bars correspond to \pm 1 standard deviation.

is the broad winter maximum which occurs in the western Mediterranean basin, starting in October and extending up to May; these winter $a_{y}$ values are almost twice those in the corresponding Atlantic sector. In contrast, the summer minima in $a_{y}$ are practically identical in the western Mediterranean and in the northern eastern Atlantic.

In the eastern Mediterranean basin, the winter $a_{y}$ maximum is sharper and coincides with the Levantine algal bloom (February). The summer (Jul-Aug-Sep) mean values in this basin $\left(a_{y}(443) \sim 0.013 \mathrm{~m}^{-1}\right.$, Fig. 3) are hardly above those $\left(0.010 \mathrm{~m}^{-1}\right)$ in the southern Atlantic zone, which themselves are not far from those observed in the Sargasso Sea by Nelson et al. (2007). Indeed, these authors observed at $325 \mathrm{~nm}$ yellow substance absorption coefficients amounting to about $0.06 \mathrm{~m}^{-1}$, approximately equivalent to $a_{y}(443) \sim 0.01 \mathrm{~m}^{-1}$. So, the eastern Mediterranean would be almost as blue as the Sargasso Sea, at least in summer.
The seasonal cycles for 2006 within the Mediterranean basins as well as within the Atlantic zones (Fig. 3) are repeated from year to year without notable modifications (Fig. 4). The remarkable differences in the CDOM index $(\Phi)$ and concentration $\left(a_{y}\right)$, between the two geographical areas, clearly appear to be permanent features. Interestingly, the summer $a_{y}(443)$ values in the Mediterranean basins and in their Atlantic counterparts are practically identical; therefore, the strong Mediterranean vs. Atlantic contrast (Fig. 4c, d) ultimately results from the differing yellow substance contents in wintertime. As for the Mediterranean sea itself (Fig. 4c), the two basins are not identical; in all seasons, the $a_{y}(443)$ coefficients of the western basin exceed those of the eastern basin, by about $50 \%$. 

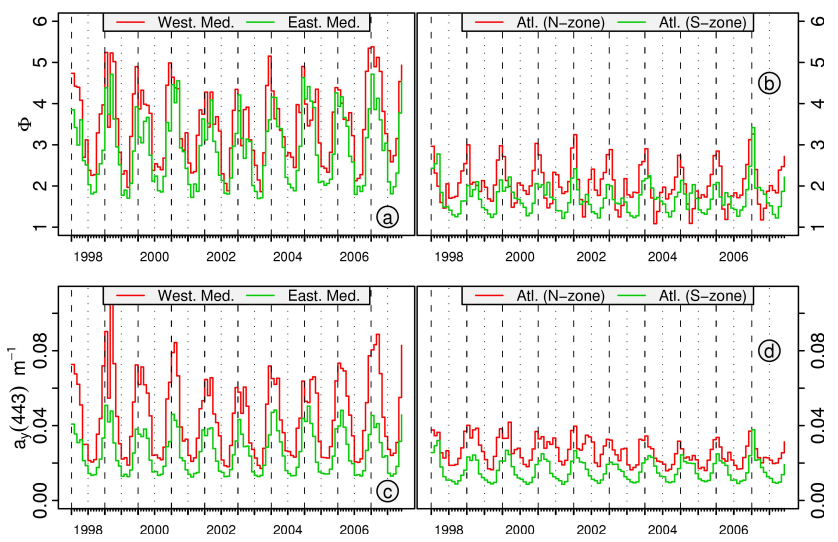

Fig. 4. Time series over a 10 -year period of $(\mathbf{a}, \mathbf{b})$ the $\Phi$ factor, and (c, d) of the absorption coefficient by yellow substance, $a_{y}(443)$. Monthly averaged SeaWiFS data were used; they were separately averaged for the Western and Eastern Mediterranean basins, and for the Northern and Southern sectors within the Eastern Atlantic, as indicated.

The absorption coefficients at $443 \mathrm{~nm}$ of the dissolved plus particulate (detrital) organic matter, as retrieved via the "GSM" method (Siegel et al., 2002) and denoted $a_{\mathrm{CDM}}$ by these authors, exhibit the same inter-regional differences; they also follow the same seasonal patterns (not shown, visualized via the Giovanni tool http://reason.gsfc.nasa.gov/ Giovanni/). Compared to those of $a_{y}$, the $a_{\mathrm{CDM}}$ values are slightly lower, particularly during the blooms, but they remain within the dispersion affecting the $a_{y}$ values.

As already explained in detail (Morel and Gentili, 2009), the variations in $\Phi$ lead to biased estimates of [Chl] when $[\mathrm{Chl}]$ is retrieved by applying standard algorithms, that implicitly have included the hypothesis $\Phi=1$. With $\Phi$ generally well above 1 in the Mediterranean Sea, and thus with an excess of CDOM compared to the standard value as prescribed by Eq. (1), the corrections result in diminishing the OC4v4 [Chl] estimates (the converse holds true when $\Phi<1$ ). When $\Phi \sim 4$, the correction can reach $-50 \%$ (Fig. 9, in Morel and Gentili, 2009). In both the Mediterranean basins, such a halving happens in winter and early spring (last row in Fig. 3), while the reduction is less in summertime $(\sim-20 / 30 \%)$. After correction, the [Chl] values, averaged over the entire Eastern basin, would not exceed $0.12 \mathrm{mg} \mathrm{m}^{-3}$ in February-March, and remain almost constant (around $0.065 \mathrm{mg} \mathrm{m}^{-3}$ ) for the rest of the year, thus confirming the oligotrophic status of this province. In the Western basin, the bloom peaking in March is considerably reduced when corrected (average value $0.25 \mathrm{mg} \mathrm{m}^{-3}$ versus the initial value around $0.47 \mathrm{mg} \mathrm{m}^{-3}$ ); thereafter [Chl] remains roughly constant amounting on average to $\sim 0.12 \mathrm{mg} \mathrm{m}^{-3}$. Importantly, the strong progressive increase in [Chl] from September to January, that appears in both basins through the use of standard algorithms, is largely smoothed out after correction, in such a way that the bloom in March (Western basin) emerges as a more isolated feature. Actually, field data in the northern part of the western basin (Marty et al., 2002; Antoine et al., 2008) do not indicate a regular and so abrupt algal biomass increase during autumn; instead they tend to support the corrected values. It is also worth noting that the northern Atlantic sector, where the $\Phi$ and $a_{y}$ values are notably below those of Mediterranean, exhibits the most prominent [Chl] peak during the spring bloom (in April), almost unaffected by the CDOM correction; sometimes, the correction may become positive, when $\Phi$ is locally $<1$ (e.g., along the $38^{\circ} \mathrm{N}$ line in Atlantic; cf. Fig. 2 for March 2006).

\subsection{Yellow substance index and regionally tuned algorithms}

To reconcile the field and satellite determinations of [Chl] in the Mediterranean Sea, regional algorithms were empirically proposed; they were simply based on regression analyses of blue-to-green reflectance ratios, such as $R_{555}^{443}$ (in Gitelson et al., 1996; or Bricaud et al., 2002), or $R_{555}^{490}$ (in D'Ortenzio et al., 2002), or MBR (Maximum band ratio, in Volpe et al., 2007) versus field determinations of [Chl]. These empirical relationships were used by these authors instead of the algorithms regularly operated at global scale by Space Agencies. They provided more realistic [Chl] values when compared to the overestimated concentrations returned by the routine algorithms. It is thus logical to examine to what extent the yellow substances excess detected in the Mediterranean is able to perturb the returns of the standard algorithms, and correlatively, whether the empirically algorithms actually reflect in their tuned version the influence of an excess in CDOM.

For that purpose, the bio-optical model for Case-1 waters (MM-01) is operated to get the spectral reflectance as a function of [Chl], and produce the ratios of reflectances which are successively considered in the MBR algorithm (O'Reilly et al., 2000). The result is the semi-analytical OC4Me555 algorithm (already presented in Morel et al., 2007b), which differs only slightly from the purely empirical algorithm OC4v4 employed with SeaWiFS data. The obvious advantage of using the semi-analytical approach (compared to empirical approach) is the possibility of simulating "perturbations" and examining their effects. The first perturbation here considered consists of increasing the partial absorption due to CDOM (by letting $\Phi>1$ ); the results are graphically shown in Fig. 5a. Besides the unperturbed nominal algorithm (i.e., when $\Phi=1$ ), the curves corresponding to $\Phi=2$ and 4 are also drawn. They can be compared with the regional algorithms, which roughly agree with the modeled algorithm when a doubling in CDOM $(\Phi=2)$ has been introduced. This agreement demonstrates that the empirically tuned algorithms actually reflect the influence of an above average CDOM content, even if they were not purposely developed under this hypothesis. Another scenario, however, must be envisaged, by which CDOM would stay 

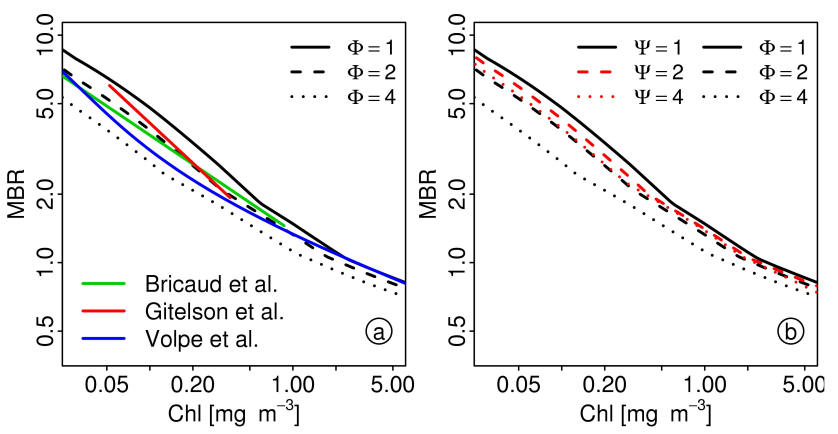

Fig. 5. Maximum band ratio algorithm (OC4Me555, Morel et al., 2007b) for the retrieval of [Chl]; the nominal algorithm (black solid curve) is for the average standard situation in terms of CDOM content (i.e., when $\Phi=1$ ); this content is doubled, or multiplied by 4 , for the dashed curve and the dotted black curve, respectively. In (a), the green straight line represents the regionally tuned algorithm, proposed and used by Bricaud et al., (2002), namely $[\mathrm{Chl}]=2.094\left(R_{555}^{443}\right)^{-2.357}$ the red straight line represents the regionally tuned algorithm, proposed and used by Gitelson et al. (1996), namely $[\mathrm{Chl}]=0.914\left(R_{550}^{440}\right)^{-1.86}$ The MBR algorithm ("MedOC4") proposed by Volpe et al. (2007) is represented by the blue curve. In (b) , the dashed and dotted red curves are derived from the nominal algorithm (black curve) when the particle backscattering is doubled ( $\Psi=2)$ or multiplied by $4(\Psi=4)$. the dashed and dotted black curves are as in (a).

at its standard level, while the particle backscattering coefficient, $b_{b p}$, would be modified. This hypothesis was already examined in Morel and Gentili (2009): in this intent, they introduced a perturbation, represented by $\Psi$ (either $<1$ or $>1$ ), which is the ratio of the modified $b_{b p}$ coefficient to its standard, [Chl]-dependent, value. By operating the MM-01 model, the modified MBR $\leftrightarrow[\mathrm{Chl}]$ relationships can be produced for various $\Psi$ values, as it was made for $\Phi$. Increasing $\Psi$ above 1 produces an effect in the same direction as that observed when increasing $\Phi$, but the amplitude of this effect is much lesser (Fig. 5b). For instance, the position (in Fig. 5a) of the empirical algorithm proposed by Bricaud et al. (2002) can be explained if the CDOM content is doubled (as said above), but if the change in particle backscattering is presumed to be the cause of the shifted algorithm, a more considerable increase of $b_{b p}$ must be considered (approximately by a factor $\Psi=5$ ).

Nevertheless, it cannot be dismissed that the difference between the regionally derived relationships and the regular algorithm does not reflect exclusively a change in yellow substance concentration. Indeed, an enhanced backscattering, $b_{b p}$, was hypothesized by Gitelson et al. (1996), whereas the effect of calcite was also examined by D'Ortenzio et al. (2002). Actually, the couples of wavelengths involved in the maximum band ratio, or in the above empirical regional algorithms (namely $443-555$ or $490-555 \mathrm{~nm}$ ), cannot provide an efficient mean to discriminate the cause of the anomaly (either CDOM, or backscattering). To be
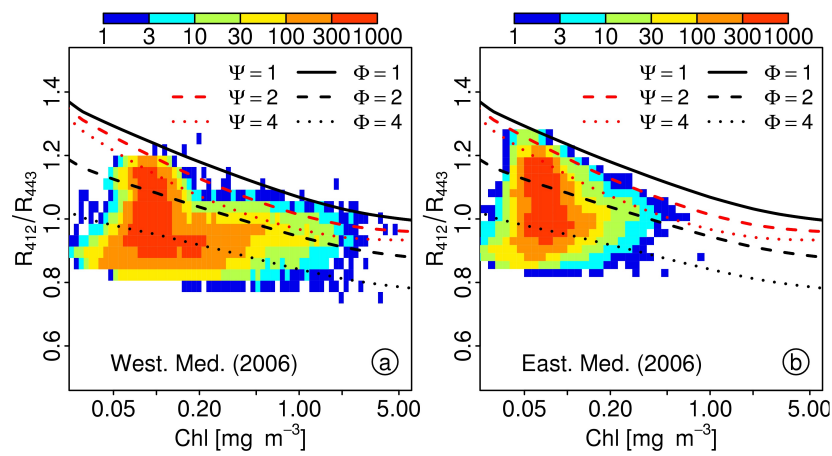

Fig. 6. Computed relationships between $R_{443}^{412}$ and [Chl], for the standard situation (solid black curve, with $\Phi$ and $\Psi=1$ ), and for the situations modified by increasing the CDOM content (dashed and dotted black curves, with $\Phi=2$ and 4 , respectively), or modified by increasing the particle backscattering (dashed and dotted red curves, with $\Psi=2$ and 4 , respectively). Superimposed are the $R_{443}^{412}$ and [Chl] values extracted from the pixels in the western (a) and the eastern Mediterranean (b) basins during the 12 months of the year 2006. The number of occurrences is visualized through the frequency color scale; the total number of pixels represented in each basin is about $1.410^{5}$ ).

efficient a tool must involve the $412 \mathrm{~nm}$ band, which is particularly sensitive to the yellow substances presence and concentration. This is demonstrated by Fig. 6a, b, where the modeled $R_{443}^{412}$ ratio is plotted as a function of [Chl]. Beside the nominal relationship (when $\Phi$ and $\Psi=1$ ), are shown the modified relationships, namely when $\Phi=2$ and 4 (while $\Psi=1$ ), or when $\Psi=2$ and 4 (while $\Phi=1$ ). Changes in the backscattering coefficient result in reduced modifications compared to those induced by changes in CDOM. The Sea$\mathrm{WiFS}$ data $\left(R_{443}^{412}\right.$ and [Chl]) for the year 2006, taken as examples, are also displayed. Two features are particularly significant: i) the actual $R_{443}^{412}$ ratios seldom reach the ceiling curve which would correspond to a standard situation with $\Phi=1$, and ii) their distance from this curve is such that a (moderate) excess of yellow substance is the most plausible explanation to the observed departures, rather than a huge $b_{b p}$ increase needed to generate departures of similar amplitude. Anyway, if existing, such large excesses in backscattering would have inevitably been detected (and the corresponding pixels flagged) when the turbidity criterion was applied.

An additional confirmation of the crucial role of yellow absorbing substance(s) can be found by comparing the distribution of the same (SeaWiFS, 2006) data in Fig. 1b with the theoretical curves of Fig. 2c in Morel and Gentili (2009). In the latter, it can be seen that when [Chl] is $<0.25 \mathrm{mg} \mathrm{m}^{-3}$ approximately (i.e., when $R_{555}^{490}>2.5$ ), the impact of changes in $\Psi$ becomes extremely weak. This is a logical consequence of the predominance of the backscattering by water molecules over the particle backscattering in this low-[Chl] range. Most of the pixels in the Mediterranean Sea fall in this range, and thus are rather insensitive to changes in $\Psi$ (if any). 


\section{Discussion and conclusion}

The major initial motivation of the present study was to understand why the ocean color radiometry applied to the Mediterranean Sea has recurrently provided data contradicting the historically acknowledged low Chlorophyll concentration. This contradiction was maintained when contemporaneous [Chl] measurements performed at sea during several cruises were compared to satellite returns (e.g., Claustre et al., 2002). Among the potential causes invoked to account for such a discrepancy, an "anomalously" high yellow substance content compared to oceanic average values was a plausible candidate. This hypothesis has been tested by operating and applying to SeaWiFS data a recently proposed method capable of detecting such an excess. As a first conclusion, it appears that a notable yellow substance excess does exist in both basins of the Mediterranean Sea when they are compared with the neighboring Atlantic sectors. This excess explains why the standard algorithms have generally overestimated [Chl], and also how regionally tuned algorithms have been able to return more realistic values.

A first discussion necessarily deals with the accuracy of the present results and their numerical significance. As already underlined when describing the method here employed (Morel and Gentili, 2009), the quality of the retrieved marine signal at $412 \mathrm{~nm}$ is crucial, as a component of the $R_{443}^{412}$ ratio. Unfortunately, beside the sensor calibration problem, achieving an accurate atmospheric correction at this wavelength is a difficult task so that the assessment of the marine signal may be affected. The difficulty actually increases when the air mass increases, i.e., when the sun-zenith angle and the viewing angle increases (Wang, IOCCG Report, 2009). A recent match-up analysis of satellite derived reflectances compared with in situ radiometric observations (Antoine et al., 2008) showed that the poorest performances are precisely observed for this $412 \mathrm{~nm}$ channel. For the three major sensors (SeaWiFS, MODIS-A, and MERIS), the scatter of the satellite values compared with field values (Fig. 9, and Tables 2, 3, and 4 , ibid.) is larger at $412 \mathrm{~nm}$ than at any other wavelength, and in addition, the three sensors behave differently. For instance, the MERIS reflectances at $412 \mathrm{~nm}$ are considerably overestimated with an average MERIS-to-in situ data ratio amounting to about 1.60 (and 1.32 and $443 \mathrm{~nm}$ ). In contrast, this ratio is closer to unity ( 0.92 for SeaWiFS, and 0.90 for MODIS-A), likely because these sensors have been vicariously calibrated on orbit, which is not yet the case for MERIS. As an overestimate of the marine reflectance at $412 \mathrm{~nm}$, and hence of the $R_{443}^{412}$ ratio, leads to a reduction of the $\Phi$ factor, and subsequently of the $a_{y}(443)$ values, it is not surprising that the $a_{y}(443)$ values derived from MERIS data (not shown) are systematically below those derived from SeaWiFS; the divergence increases in winter when the sunzenith angle reaches its highest values $\left(\sim 70^{\circ}\right.$ for MERIS, according to its orbit phasing) in the northern part of the Mediterranean basins. The examination of the atmospheric correction performance at the bluest wavebands is a topic in itself, and a difficult topic, out of the scope of the present study. It is worth noting that the results here presented actually rest on the use of a single sensor and a single atmospheric scheme, developed for SeaWiFS, which at least allows an internal consistency of the results to be preserved. This caution regarding the quality of the violet signal, however, has to be kept in mind and justifies the previous recommendation of considering the relative variations from zones to zones, rather than the absolute $a_{y}(443)$ values.

Systematic and reliable field measurements of $a_{y}(443)$ in the Mediterranean Sea and neighboring Atlantic are not yet available to consolidate the satellite derived values. Some $a_{y}(443)$ determinations near the Canary islands were published (Babin et al., 2003) amounting to about $0.01 \mathrm{~m}^{-1}$, whereas within and off the Rhone river plume values ranged from 0.1 to $0.01 \mathrm{~m}^{-1}$. A few data obtained in the near surface layer (and at $\lambda=300 \mathrm{~nm}$ ) in the NE Atlantic subtropical gyre and in the oligotrophic Cyprus gyre (Eastern Mediterranean) (Kitidis et al., 2006a, b) are compatible with those obtained here at $443 \mathrm{~nm}$. The uncertainties when extrapolating the $a_{y}$ values $\left(\sim 0.23 \mathrm{~m}^{-1}\right)$, from $300 \mathrm{~nm}$ toward $443 \mathrm{~nm}$, prevent from going beyond a rough qualitative statement. Indirect estimates via field values of the spectral reflectance and attenuation coefficient in the blue and near UV domains (Morel et al., 2007a), however, convincingly supported the existence of high yellow substances content in the Mediterranean Sea compared to that in Pacific Ocean.

Even if the enigmatic failure in the remote assessment of [Chl] in the Mediterranean Sea, and the presumably peculiar optical properties in this area have formed the main motivations of the present paper, it is difficult to dodge the issue of the origin of such a singularity. A second discussion will briefly deal with this geochemical aspect. The main specific traits can be summarized as follows; i) the yellow substance level in the Mediterranean Sea is about twice that of nearby oceanic waters with similar trophic conditions, ii) the level is higher in the western basin than in the eastern basin, and inside the western basin the level is higher in the northern zone compared to the southern zone, iii) there is everywhere a pronounced seasonal signal, mainly shaped by the strong depression during summer, superimposed upon a background of high values.

First of all, the sources and sinks of yellow substances in the open ocean, as well as the (physical, chemical, biological) interactions regulating its concentration and distribution remain largely elusive (e.g., discussion in Nelson and Siegel, 2002). This general statement obviously continues to hold true as far as the Mediterranean Sea is concerned. A clue, perhaps, to get some insight into the question of a higher CDOM content could be to examine what are the specificities of this semi-enclosed sea.

The possibility that such a CDOM background (and particularly its truly dissolved fraction) may have a significant terrestrial component is to be considered. As suggested by 
Siegel et al. (2002) for instance, the differences in the bulk concentration in the North Atlantic Ocean and in the North Pacific Ocean could plausibly originate from differences in riverine inputs, 3 times greater in the former zone than in the latter. Is such a similar explanation applicable to the Mediterranean Sea, and to the contrast between this sea and the neighboring Atlantic?

To examine this question, the water discharge of the major world rivers are considered; they are taken in Cauwet (2002), and the oceanic areas in Sverdrup et al. (1963). From these data it can be inferred that the annual mean river discharges is equivalent to a layer of about $180 \mathrm{~mm} \mathrm{yr}^{-1}$ for the ocean within the Northern Hemisphere (including its Arctic and Baltic regions), and $27 \mathrm{~mm} \mathrm{yr}^{-1}$ for the ocean within the Southern Hemisphere; note that such computations assume that the two oceanic hemispheres are hypothetically disconnected. The dissymmetry in the oceanic distribution of CDOM, with higher mean concentration in the Northern Hemisphere, compared to that in the Southern Hemisphere (e.g., Fig. 4 in Siegel et al., 2002, and Fig. 5, and 6c in Morel and Gentili, 2009) could thus originate from the dissymmetry in the river impact. The same kind of computation for the ensemble Mediterranean Sea plus Black Sea leads to an annual river discharge equivalent to approximately $135 \mathrm{~mm} \mathrm{yr}^{-1}$ (100 $\mathrm{mm} \mathrm{yr}^{-1}$ in Mariotti et al., 2002). This value is thus below the average for the entire Northern Hemisphere, that admittedly is geographically biased, by its arctic water budget. Such a value, however, is probably above the typical values for the same $\left(30-45^{\circ} \mathrm{N}\right)$ band in the near-Atlantic, but this assumption cannot be easily verified. Therefore, the riverine contribution in the formation of a high level in yellow absorbing substances is a plausible explanation, but not a decisive one.

An exceptional trait of the Mediterranean hydrology is the formation of specific deep waters and bottom waters which occur in winter within the coldest northernmost parts of the basins. The most active convection occurs in the gulf of Lions and results in the formation of the deep water for the western basin. In north Aegean and Adriatic seas similar processes lead to the formation of the deep water of the eastern basin, whereas the Levantine intermediate water is formed in the vicinity of the island of Rhodes (see e.g., Lacombe and Tchernia, 1972). These zones are the seat of deep vertical convections in winter, followed thereafter by vernal algal blooms supported by the upward flux of nutrients. During the convection episodes, a vertical transport of deep (not bleached) yellow substance occurs (Nelson and Siegel, 2002) and may account for its enhancement within the upper layers, more accentuated in the western basin where the vertical mixing process is more active than in the eastern basin. The North-South dissymmetry in the $a_{y}$ distribution is also coherent with the N-S dissymmetry in the vertical convection processes. Actually, the maxima in $a_{y}$ are progressively built during the autumnal period, and apparently are associated with the erosion and deepening of the pycnocline, rather

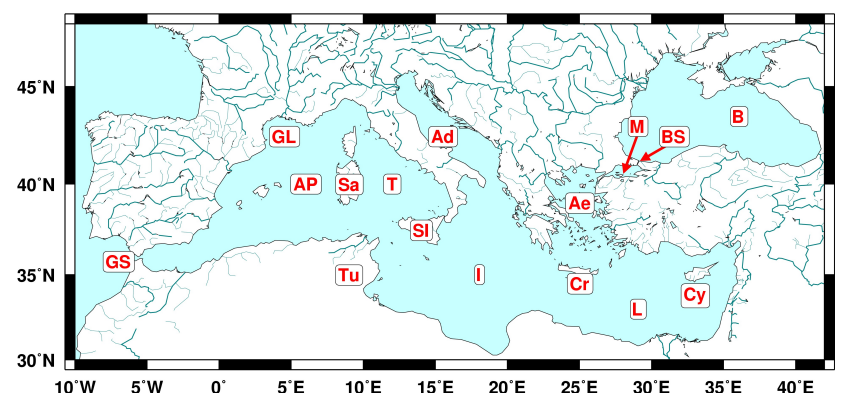

Fig. A1. Map of the Mediterranean Sea and approximate location of the geographical features mentioned in the text. The meaning of the abbreviation is as follows (alphabetical order): $\mathrm{Ad}=$ Adriatic Sea, $\mathrm{Ae}=$ Aegean Sea; $\mathrm{AP}=$ Algero-Provencal basin; $\mathrm{B}=$ Black Sea; $\mathrm{BS}=$ Bosporus Strait $; \mathrm{Cr}=$ Crete island; $\mathrm{Cy}=$ Cyprus island; GL = Gulf of Lions; GS = Gibraltar Strait; I=Ionian Sea; $\mathrm{L}=$ Levantine basin; $\mathrm{M}=$ Marmora Sea; $\mathrm{Sa}=$ Sardinia; $\mathrm{Si}=$ Sicily; $\mathrm{T}=$ Thyrrhenian $\mathrm{Sea} ; \mathrm{Tu}=$ Tunisia .

than with the vernal algal blooms which occur later, more abruptly, and when stratification set up.

According to its latitude, the Mediterranean region experiences a contrasted seasonal cycle, with high sunshine and cloudless skies in summer, particularly in its southern parts engaged into the semiarid climate belt. Combined with the stratification of the water column, the strong solar flux in summer is able to explain, via the photochemical bleaching process, the precipitous decrease in both basins of $\Phi$ and $a_{y}$ from their maxima in winter to a flat minimum extended from July to September. A similar process comes into play everywhere at the same latitude, in Atlantic for instance. It appears to be more marked in the Mediterranean Sea, but this appearance is perhaps due to the fact that the initial (i.e., winter) background in Mediterranean is higher than in Atlantic, so that the winter-summer contrast is enhanced.

There are not presently adequate biochemical information nor in situ determinations, including at depth, to consolidate the above attempts to explain the yellow substance levels and their cycles in the Mediterranean Sea and in the near Atlantic. Nevertheless, their comparative detection, which was the aim of the present work, is clearly established. The resulting inaccuracy in the assessment of [Chl] is also demonstrated, and, if not accounted for, leads to a non negligible readjustment of the algal biomass estimate, and thus of the productivity in this Sea. 
Acknowledgements. We are indebted to D. Antoine for useful suggestions on a first draft of the present paper. We wish to thank three anonymous reviewers for helpful questions and comments.

Edited by: E. Marañón

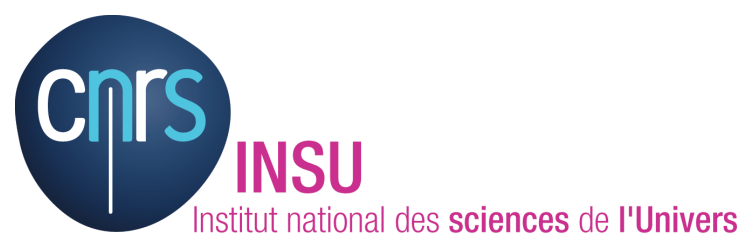

The publication of this article is financed by CNRS-INSU.

\section{References}

Antoine, D., Morel, A., and André, J. M.: Algal Pigment Distribution and Primary Production in the Eastern Mediterranean as Derived from Coastal Zone Color Scanner Observations, J. Geophys. Res.-Oceans, 100, 16193-16209, 1995.

Antoine, D., D’Ortenzio, F., Hooker, S. B., Bécu, G., Gentili, B., Tailliez, D., and Scott, A. J.: Assessment of uncertainty in the ocean reflectance determined by three satellite ocean color sensors (MERIS, SeaWiFS, and MODIS-A) at an offshore site in the Mediterranean Sea, J. Geophys. Res., 113, C07013, doi:101029/2007JC004472, 2008.

Babin, M., Stramski, D., Ferrari, G. M., Claustre, H., Bricaud, A., Obolensky, G., and Hoepffner, N.: Variations in the light absorption coefficients of phytoplankton, non-algal particles, and dissolved organic matter in coastal waters around Europe, J. Geophys. Res., 108, C7-3211, doi:10.1029/2001JC000882, 2003.

Bethoux, J. P.: Budgets of the Mediterranean Sea: Their dependence on the local climate and on the characteristics of the Atlantic waters, Oceanol. Acta, 2, 157-163, 1979.

Bricaud, A., Morel, A., Babin, M., Allali, K., and Claustre, H.: Variations of light absorption by suspended particles with chlorophyll a concentration in oceanic (case 1) waters: Analysis and implications for bio-optical models, J. Geophys. Res.-Oceans, 103, 31033-31044, 1998.

Bricaud, A., Bosc, E., and Antoine, D.: Algal biomass and sea surface temperature in the Mediterranean basin: Intercomparison of data from various satellite sensors, and implications for primary production estimates, Remote Sens. Environ., 81, 163-178, 2002.

Claustre, H., Morel, A., Hooker, S. B., Babin, M., Antoine, D., Oubelkheir, K., Bricaud, A., Leblanc, K., Queguiner, B., and Maritorena, S.: Is desert dust making oligotrophic waters greener?, Geophys. Res. Lett., 29, 1469, doi:10.1029/2001GL014056, 2002.

Claustre, H. and Maritorena, S.: The many shades of ocean blue, Science, p. 302, 1514-1515, 2003.

Cauwet, G.: DOM in the coastal zone, in: Biochemistry of marine dissolved organic matter, edited by: Hansell, D. A. and Carlson, C. A., Academic Press, San Diego, 579-609, 2002.

D’Ortenzio, F., Marullo, S., Ragni, M., Ribera d'Alcala, M., and Santoleri, R.: Validation of empirical SeaWiFS algorithms for chlorophyll a retrieval in the Mediterranean Sea: A case study for oligotrophic seas, Remote Sens. Environ., 82, 79-94, 2002.

Gitelson, A., Karnieli, A., Goldman, N., Yacobi, Y. Z., and Mayo, M.: Chlorophyll estimation in the Southeastern Mediterranean using CZCS images: Adaptation of an algorithm and its validation, J. Marine Syst., 9, 283-290, 1996.

Gregg, W. and Casey, N. W.: Global and regional evaluation of the SeaWiFS chlorophyll data set, Remote Sens. Environ., 93, 463479, 2004.

Hu, C., Lee, Z., Muller-Karger, F. E., Carder, K. L., and Walsh, J. J.: Ocean color reveals phase shift between marine plants and yellow substance, IEEE Geosci. Remote S., 3, 262-266, 2006.

IOCCG: Atmospheric correction for the remote sensing of ocean color products, M. Wang, WG Chairman, Reports of the International Ocean Colour Coordinating Group, V. Stuart, Ed., Dartmouth, Nova Scotia, Canada, 2009.

Kitidis, V., Stubbins, A. P., Uher, G., Goddard, R. C. U., Law, C. S., and Woodward, E. M. S.: Variability of chromophoric organic matter in surface waters of the Atlantic Ocean, Deep-Sea Res. Pt. II, 53, 1666-1684, 2006a.

Kitidis, V., Uher, G., Upstill-Goddard, R. C., Mantoura, R. F. C., Spyres, G., and Woodward, E. M. S.: Photochemical production of ammonium in the oligotrophic Cyprus Gyre (Eastern Mediterrranean), Biogeosciences, 3, 439-449, 2006b, http://www.biogeosciences.net/3/439/2006/.

Lacombe, H. and Tchernia, P.: Caractères hydrologiques et circulation des eaux en Méditerranée, in: The Mediterranean Sea: A natural sedimentation laboratory, edited by: Stanley, D. J., 2536, 1972.

Lee, Z. P. and Hu, C.: Global distribution of Case-1 waters: An analysis from SeaWiFS measurements, Remote Sens. Environ., 101, 270-276, 2006.

Mariotti, A., Struglia, M. V., Ning, Z., and Lau, K. M.: The hydrological cycle in the Mediterranean region and implications for water budget of the Mediterranean Sea, J. Climate, 15, 1674 1690, 2002.

Marty, J. C., Chiaverini, J., Pizay, M.-D., and Avril, B.: Seasonal and interannual dynamics of nutrients and phytoplankton pigments in the western Mediterranean Sea at the DYFAMED timeseries station (1991-1999), Deep-Sea Res. Pt. II, 49, 1965-1985, 2002.

Morel, A. and Maritorena, S.: Bio-optical properties of oceanic waters: A reappraisal, J. Geophys. Res.-Oceans, 106, 7163-7180, 2001.

Morel, A. and Gentili, B.: Radiation transport within oceanic (Case 1) waters, J. Geophys. Res., 109, C6, C06008, doi:10.1029/2003JC002259, 2004.

Morel, A. and Belanger, S.: Improved detection of turbid waters from ocean color sensors information, Remote Sens. Environ., 102, 237-249, 2006.

Morel, A., Claustre, H., Antoine, D., and Gentili, B.: Natural variability of bio-optical properties in Case 1 waters: Attenuation and reflectance within the visible and near-UV spectral domains as observed in South Pacific and Mediterranean waters, Biogeosciences, 4, 2147-2178, 2007a, http://www.biogeosciences.net/4/2147/2007/.

Morel, A., Huot, Y., Gentili, B., Werdell, P. J., Hooker, S. B., and Franz, B. A.: Examining the consistency of products derived from various ocean color sensors in open ocean (Case 1) waters 
in the perspective of a multi-sensor approach, Remote Sens. Environ., 111, 69-88, 2007b.

Morel, A., Gentili, B., Claustre, H., Babin, M., Bricaud, A., Ras, J., and Tièche, F.: Optical properties of the "clearest" natural waters, Limnol. Oceanogr., 52, 217-229, 2007c.

Morel, A.: Are the empirical laws describing the bio-optical properties of Case 1 waters consistent and internally compatible?, J. Geophys. Res., 114, C01016, doi:10.1029/2008JC004803, 2009.

Morel, A. and Gentili, B.: A simple band ratio technique to quantify the colored dissolved and detrital organic material from ocean color remotely sensed data, Remote Sens. Environ., 113, 9981011, doi:101016/j.rse.2009.01.008, 2009.

Nelson, N. B. and Siegel, D. A.: Chromophoric DOM in the open ocean, edited by: Hansell, D. A. and Carlson, C. A., in: Biogeochemistry of marine dissolved organic matter, Academic Press, San Diego, 547-578, 2002.

Nelson, N. B., Siegel, D. A., Carlson, C. A., Swan, C., Smethie Jr, W. M., and Khatiwala, S.: Hydrography of chromophoric dissolved organic matter in the North Atlantic, Deep-Sea Res. Pt. I, 54, 710-731, 2007.

Opsahl, S. and Benner, R.: Distribution and cycling of terrigenous dissolved organic matter in the ocean, Nature, 386, 480-482, 1997.

O’Reilly, J. E., Maritorena, S., Mitchell, B. G., Siegel, D. A., Carder, K. L., Garver, A., Kahru, M., and McClain, C.: Ocean color algorithms for SeaWiFS, J. Geophys. Res., 103, 2493724953, 1998.
O'Reilly, J. E., Maritorena, S., Siegel, D., O'Brien, M. C., et al.: Ocean color chlorophyll a algorithms for SeaWiFS, OC2, and OC4: version 4., SeaWiFS postlaunch calibration and validation analyses, Part 3, NASA/TM 206892, 11, 9-23, 2000.

Pope, R. M. and Fry, E. S.: Absorption spectrum (380-700 nm) of pure water, II, integrating cavity measurements, Appl. Optics, 36, 8710-8723, 1997.

Siegel, D. A., Maritorena, S., Nelson, N. B., Hansell, D. A., and Lorenzi-Kayser, M.: Global ocean distribution and dynamics of colored dissolved and detrital organic material, J. Geophys. Res., 107(C12), 3328, doi:1029/2001JC000965, 2002.

Siegel, D. A., Maritorena, S., Nelson, N. B., and Behrenfeld, M. J.: Independence and interdependencies among global ocean color properties: Re-assessing the bio-optical assumption, J. Geophys. Res., 110, C07011, doi:10.1029/2004JC002527, 2005.

Sverdrup, H. U., Johnson, M. W., and Fleming, R. H.: The oceans, (1087), Prentice-Hall, Inc., 1963.

Volpe, G., Santoleri, R., Velluci, V., Ribera d'Alcala, M., Marullo, S., and D'Ortenzio, F.: The colour of the Mediterranean Sea: Global versus regional bio-optical algorithms evaluation and implication for satellite chlorophyll estimates, Remote Sens. Environ., 107, 625-638, 2007. 